\title{
A expansão do ensino a distância e os desafios para assegurar a qualidade na graduação: Um estudo realizado com Instituições de Ensino Superior em Juazeiro do Norte-CE
}

\author{
Francisca Jacqueline Soares dos Santos ${ }^{1}$; Marcus Emanuel Oliveira Lima²; Piedley Macedo Saraiva ${ }^{3}$
}

\begin{abstract}
Resumo: Este trabalho pretende analisar o ensino a distância na graduação a partir da formação dos professores, como isso pode ter influência no preconceito com essa modalidade e a garantia de sua qualidade. Expondo, assim, os desafios que estão presentes para esses tipos de curso, mesmo com o avanço tecnológico, face a necessidade da preparação dos educadores para a especificidade desse tipo de ensino. Trata-se de uma pesquisa em que foi utilizado o método históricocrítico, além da utilização da técnica de revisão bibliográfica para avaliar como se deu o avanço do Ensino a Distância e sua receptividade, relacionando com a formação docente. Dessa forma, foram utilizadas produções acadêmicas atualizadas versando sobre o tema, priorizando as que tenham sido produzidas nos últimos cinco anos, visando assim acompanhar a situação atual da sociedade e da tecnologia existente. Para alcançar o objetivo pretendido por essa pesquisa foi realizada pesquisa descritiva e os dados foram obtidos através de entrevista realizada com alunos de quatro instituições de ensino superior da cidade de Juazeiro do Norte - CE. Para melhor análise, os dados foram apresentados em gráficos. Como resultado, pode-se verificar a percepção dos alunos sobre a realização do curso de graduação à distância, identificando as características desejáveis, os recursos tecnológicos que mais contribuem para a aprendizagem, e ainda citar as principais vantagens e as dificuldades encontradas ao longo do curso.
\end{abstract}

Palavras-chave: Ensino a Distância. Recursos. Desafios.

\section{The Expansion of distance education and the challenges to ensure quality in graduation: A study carried out with Higher Education Institutions in Juazeiro do Norte-CE}

\begin{abstract}
This work aims to analyze distance education in undergraduate education from the teachers' formation, as this can influence the prejudice with this modality and the guarantee of its quality. Thus, exposing the challenges that are present for these types of course, even with technological advancement, the need to prepare educators for the specificity of this type of teaching. This is a research in which the historical-critical method was used, in addition to the use of the literature review technique to assess how the advancement of distance learning and its receptivity, relating to teacher education, was made. Thus, updated academic productions were used that deal with the theme, prioritizing those that have been produced in the last five years, in order to follow the current situation of society and existing technology. To achieve the objective intended by this research was done descriptive research, and the data were obtained through an interview that was conducted with students from four higher education institutions in the city of Juazeiro do Norte - CE. For better analysis, data were presented in graphs. As a result, it is possible to verify the students' perception about the distance learning undergraduate course, identifying the desirable characteristics, the technological resources that contribute most to the learning, and also mention the main advantages and difficulties found during the course.
\end{abstract}

Keywords: Distance learning. Resources. Challenges.

\footnotetext{
${ }^{1}$ Graduada em Administração de Empresas pela FAP - Faculdade Paraíso do Ceará com Pós-Graduação em Gestão e Docência do Ensino Superior pela Fap e espacialização em andamento em Políticas de Desenvolvimento em Gestão de Recursos Humanos pela Unileão - Centro Universitário Dr. Leão Sampaio.

${ }^{2}$ Especialista em Direito Penal e Criminologia (URCA/CE). Cursando MBA em Gestão de Conflitos, Mediação, Conciliação e Arbitragem (FAP/CE). Bacharel em Direito (FAP/CE). Graduando em Administração (FAP/CE). Advogado e Consultor Jurídico. E-mail: marcuslimajus@gmail.com

${ }^{3}$ Mestre em Gestão estrategica pela UNISAL, Cursando mestrado em Desenvolvimento regional, especilista em Docência do ensino superior, competencias gerenciais, marketing digital, graduado em administração de empresas, professor universitario da Faculdade Paraiso do Ceará. piedley@aller.co.
} 


\section{Introdução}

Diversos mecanismos foram elaborados para facilitar a transmissão de informações ao longo do tempo, com isso foi possível a comunicação epistolar, radiofônica, telefônica, televisiva até a revolução proporcionada pela internet. Esse avanço tecnológico foi transformando a maneira como as pessoas se relacionavam e assim impactou todas as áreas sociais, uma delas foi a educação. Não podendo se isolar das modificações trazidas pela era da informática, a sala de aula teve que integrá-las.

Seja pela inclusão de aparelhos tecnológicos, como notebooks ou tablets, para servir como instrumentos de estudo, ou ainda, através de websites e redes sociais, como ferramentas para pesquisa e compartilhamento de informações, o ensino conseguiu lentamente e estrategicamente acolher essas novidades. Uma das diversas formas foi a introdução do Ensino a Distância (EAD), que se trata de uma proposta recente, motivada pela comodidade, inclusão e/ou maior alcance social. Mesmo com a inovação desta modalidade como uma alternativa para o ensino presencial, ela trouxe consigo algumas problemáticas, como, por exemplo, a questão da formação docente.

Por se tratar de uma maneira diferenciada para lidar com os estudantes, é importante que existam estratégias pedagógicas que consigam transmitir as informações necessárias, sem perder a atenção do aluno e ainda possibilite a interação de modo eficaz, para que, então, se possa ter nesse tipo um ensino completo e com tanta qualidade quanto o presencial. Assim, os professores necessitam de formação qualificada e que atenda essas especificidades trazidas por essa forma de lecionar.

O Ensino a Distância teve um grande aumento da procura para os cursos de graduação, nas mais diversas áreas, e possuindo cada vez mais relevância no panorama acadêmico. Seu certificado de conclusão passa a ganhar maior notoriedade com o decorrer dos anos, devido o número crescente de graduados nessa modalidade. Isso motiva a reflexão acerca da preparação dos professores formadores desses futuros profissionais e sua contribuição para a receptividade desses cursos no mercado educacional brasileiro.

Mesmo com o aumento da tecnologia, os cursos realizados a distância carregam o estigma de não possuírem a qualidade equivalente aos cursos realizados na modalidade presencial. Isso faz com que mesmo com o crescimento das matrículas, ainda seja uma modalidade vista com preconceitos pela comunidade acadêmica. Uma das formas de romper essa barreira da 
ignorância sobre esse tipo de ensino é o investimento na formação de educadores voltada para as características desses discentes, tendo em vista a distância temporal e espacial entre eles.

Para alcançar o objetivo desse estudo foi realizado um breve panorama histórico de como o Ensino a Distância surgiu no Brasil. Assim como foi feita a análise sobre os avanços dessa modalidade nos cursos de graduação, a partir da pesquisa realizada com alunos matriculados nessa modalidade de ensino. Para que, enfim, pudesse ser dissertado sobre a influência da formação de professores para a qualidade da graduação na modalidade EAD. Utilizou-se como metodologia a revisão bibliográfica a partir de produções acadêmicas sobre o tema, encontradas a partir de bancos de dados científicos, priorizando as que tenham sido produzidas nos últimos cinco anos, visando assim acompanhar a situação atual da sociedade e da tecnologia existente.

\section{Breve Traçado Histórico do Ensino a Distância}

As primeiras gerações da educação a distância (EAD) abordaram o ensino por correspondência, rádio e televisão. Ao longo do tempo, elas foram substituídas pelas possibilidades de educação online, as quais cresceram significativamente nos últimos anos, especialmente com o aumento de tecnologias colaborativas da web 2.0, que permitiram a cocriação e a autoria em ambientes digitais. Esses recursos são utilizados em cursos totalmente à distância ou cursos mistos, os chamados blended-learning ou semipresenciais.

De acordo com Ribas (2007), as tecnologias na educação são historicamente recentes, enquanto o EAD é uma modalidade de ensino e de aprendizagem que data de muitos anos e teve seu início pelo ensino por correspondência, mas também se utilizou de recursos como o rádio e a televisão. O objetivo dessa modalidade era atingir um público mais distante dos centros urbanos e das escolas, por isso era um meio de disseminar o conhecimento sobre cursos de aperfeiçoamento e de educação profissional. Como exemplos, pode-se citar a Rádio Educativa, o Instituto Monitor, Instituto Universal Brasileiro, a Universidade do Ar e, mais tarde, o Telecurso, este já exigindo o acesso à televisão.

Os autores Vianney et al. (2003) e Aretio (2014) informam que o EAD está dividido em gerações. A primeira geração foi marcada pelo ensino por correspondência, direcionados a cursos profissionais de formação inicial e continuada e pela rádio educação com intuito de massificar a alfabetização. A segunda geração é caracterizada com a teleducação ou geração multimídia, o que antes era apresentado por meio do rádio, passa a ser apresentado pela 
televisão e pelos seus recursos de gravação de videoaulas, como as fitas VHS, além da formação inicial e continuada, essa geração abordava conteúdos de Ensino Fundamental e Médio. Assim, os estudantes poderiam ter acesso aos materiais didáticos e às aulas e realizar exames supletivos em seus estados e municípios a fim de concluir as etapas da formação educacional.

A terceira geração apresenta os ambientes interativos e o $e$-Learning, que também utiliza os recursos citados anteriormente, porém fazendo uso de ambientes virtuais de ensino e aprendizagem (AVEAs) pela Web. De acordo com Aretio (2014), a quarta geração apresenta o blended-learning, ou seja, o EAD ainda considera que os recursos virtuais e a interação online estejam presentes nos ambientes virtuais, apresentando a aprendizagem mista. De acordo com Valente (2015, p.23), híbrido significa misturado, mesclado, blended. A educação sempre foi misturada, híbrida, sempre combinou vários espaços, tempos, atividades, metodologias, públicos. Esse processo, agora, com a mobilidade e a conectividade, é muito mais perceptível, amplo e profundo: é um ecossistema mais aberto e criativo. Sendo possível ensinar e aprender de inúmeras formas, em todos os momentos, em múltiplos espaços.

A quinta fase apresenta a Educação 2.0, com a contribuição da Internet, que passa a trabalhar com inúmeras ferramentas de compartilhamento de informações porqualquer usuário. Trata-se de uma abordagem inovadora, pois até então quem criava e distribuía conteúdos na Internet eram apenas as pessoas com amplos conhecimentos em computação. Além das ferramentas de compartilhamento, surgem recursos para integração e comunicação mais acessíveis, como é o caso de redes sociais, blogues, vídeos e imagens. A sexta fase, de acordo com Aretio (2014), apresenta a aprendizagem móvel. Ela é oportunizada graças aos dispositivos móveis, como tablets e celulares, que conectados à Internet desempenham funções muito similares ao que antes apenas os computadores desenvolviam.

Para finalizar, a sétima fase apresenta os Massive Open Online Courses (MOOCs) e os recursos educacionais abertos (REAs). Entende-se que os "materiais de ensino, aprendizado e pesquisa, fixados em qualquer suporte ou mídia, que estejam sob domínio público ou licenciados de maneira aberta, permitindo que sejam utilizados ou adaptados por terceiros" (SANTOS et al, 2017, p. 35).

\section{Evolução do Ensino a Distância na Graduação}

Durante muito tempo os formandos dos cursos de graduação à distância sofriam por pertencer a um curso que pode ser malvisto pela sociedade, já que esta determinava que a sua 
qualidade de aprendizagem fosse deficiente. Na maioria das vezes isso não correspondia à realidade, porém, afetava no início de suas vidas profissionais, a partir da perspectiva que seu tempo e dedicação ao estudo não tinham o mesmo valor de quem tinha feito o curso na modalidade presencial.

Porém, a demanda por esses cursos não foi inibida, mesmo com esse obstáculo. Isso se deve às vantagens proporcionadas pelo ensino a distância, que percebe o aluno enquanto detentor de necessidades específicas que o impedem de realizar os cursos presenciais. Sendo assim, com público para os cursos, estes cresceram e se espalharam pelo país, fazendo-se necessário melhorar sua qualidade para garantir que qualquer ideia pré-concebida fosse superada.

Com os anos, além da democratização do ensino proporcionado por essa modalidade, o EAD traz consigo a autonomia na gestão do ensino, possibilitando ao aluno que faça seus próprios horários para estudo. Mesmo com tanto preconceito com os cursos à distância, quando se permite estudar por esse meio, dá-se ao aluno uma nova visão acerca da aprendizagem, que não cabe mais na forma tradicional e engessada, sendo o ensino sendo moldável às necessidades dos discentes.

Conforme a reflexão de Lobo Neto (2002), a Educação a Distância deve servir enquanto meio de conquista de autonomia do indivíduo, não bastando apenas a utilização da tecnologia para ser realmente parte da democratização do ensino. Dessa formam ultrapassa a questão do espaço e tempo, trazendo para esse tipo de educação o poder de transformação. Assim, é necessária a apropriação dos meios tecnológicos para que sirvam nesse ensino e não que se limite a isso.

Durante muito tempo, a Educação a Distância foi vista como um método inferior ao Presencial, devido à dedução que teria menos qualidade de ensino. Porém, a força do processo de aprendizagem não está na questão do espaço e tempo em que ocorrem, mas como estimula a participação desse aluno e interação geradora de conhecimento.

O Ministério da Educação determinou as Referenciais de Qualidade da Educação a Distância para que fossem autorizados os cursos de graduação. O foco é aumentar a qualidade dos processos de ensino, através da integração com políticas, diretrizes e padrões de qualidade. Como também a equipe multidisciplinar, recursos educacionais, infraestrutura e avaliação de qualidade contínua (PINO, 2017).

Tem se tornado cada vez mais comum a formação no ensino superior a distância. O aumento do número de inscrições nessa modalidade demonstra o crescimento da confiabilidade 
da qualidade na mesma. Porém, ainda há muito que se aperfeiçoar, principalmente com o avanço constante da tecnologia, que só tende a favorecer esse tipo de ensino.

\section{Receptividade dos Cursos de Graduação no Ensino a Distância}

Segundo dados do Instituto Nacional de Estudos e Pesquisas Educacionais Anísio Teixeira - INEP (2017), em 2016, havia 1 milhão e 49 mil alunos em 1662 cursos do ensino superior à distância. Assim, demonstra-se o expressivo número e quanto é importante, não só para evolução educacional do país, mas também para o desenvolvimento econômico.

Figura 1 - Perfil dos alunos dos cursos de graduação em 2013.

\begin{tabular}{|c|c|c|c|c|c|c|c|}
\hline \multirow{2}{*}{$\begin{array}{c}\text { Vinculo } \\
\text { Discente de } \\
\text { Graduaçāo }\end{array}$} & \multirow[b]{2}{*}{ Atributos } & \multicolumn{6}{|c|}{ Modalidade de Ensino } \\
\hline & & Presencial & $\begin{array}{c}\text { Frequência } \\
\text { Modal }\end{array}$ & $\begin{array}{c}\text { Total } \\
\text { Presencial }\end{array}$ & a Distância & $\begin{array}{c}\text { Frequência } \\
\text { Modal }\end{array}$ & $\begin{array}{c}\text { Total a } \\
\text { Distância }\end{array}$ \\
\hline \multirow{4}{*}{ Matriculas } & Sexo & Feminino & 3.416 .238 & \multirow{4}{*}{6.152 .405} & Feminino & 764.511 & \multirow{4}{*}{1.153 .572} \\
\hline & $\begin{array}{c}\text { Categoria } \\
\text { Administrativa }\end{array}$ & Privada & 4.374 .431 & & Privada & 999.019 & \\
\hline & Grau Acadêmico & Bacharelado & 4.551 .108 & & Licenciatura & 451.193 & \\
\hline & Turno & Noturno & 3.879 .203 & & n.a. & n.a. & \\
\hline \multirow{4}{*}{ Ingressos } & Sexo & Ferninino & 1.216 .445 & \multirow{4}{*}{2.227 .545} & Feminino & 321.665 & \multirow{4}{*}{515.405} \\
\hline & $\begin{array}{c}\text { Categoria } \\
\text { Administrativa }\end{array}$ & Privada & 1.732 .605 & & Privada & 478.499 & \\
\hline & Grau Acadêmico & Bacharelado & 1.584 .909 & & Tecnológico & 194.069 & \\
\hline & Turno & Noturno & 1.477 .316 & & n.a. & n.a. & \\
\hline \multirow{4}{*}{ Concluintes } & Sexo & Feminino & 491.738 & \multirow{4}{*}{829.938} & Feminino & 108.970 & \multirow{4}{*}{161.072} \\
\hline & $\begin{array}{c}\text { Categoria } \\
\text { Administrativa }\end{array}$ & Privada & 623.677 & & Privada & 138.055 & \\
\hline & Grau Acadêmico & Bacharelado & 552.060 & & Licenciatura & 61.317 & \\
\hline & Turno & Noturno & 551.835 & & n.a. & n.a. & \\
\hline
\end{tabular}

Fonte: INEP, 2013.

A Figura 1 demonstra o crescimento da procura pelos cursos superiores oferecidos por instituições de EAD. Contribuindo para o crescimento e melhoria da educação superior brasileira, os números crescentes tornam possível a dedução de que é proporcional o aumento da confiança nesses cursos e nos profissionais formados por eles. 
e obtivesse uma educação formadora. Foi através de muito trabalho e persistência que se confirmou o contrário. A oferta dos cursos em EAD aumenta de modo expressivo a cada ano. Hoje, o ensino a distância possibilita comodidade, flexibilidade e economia de tempo às pessoas que procuram uma oportunidade, mas não podem estudar de forma presencial (LEITE; ROSA, 2017, p. 183).

Assim, demonstram os autores que mesmo com as dificuldades postas para o reconhecimento de qualidade do curso a distância, com perseverança dos profissionais envolvidos e do desempenho demonstrado dos que se formaram nesses cursos, foi possível reverter esse quadro. O EAD passa a ser visto por suas qualidades enquanto uma modalidade de ensino, de maneira completa e possível para aqueles que a escolherem ou dela necessitaram.

Mesmo com a evolução tecnológica e o aumento de qualidade dos cursos realizados a distância, ainda carregam o estigma de ser posto como inferiores aos cursos presenciais. É algo baseado em preconceito enraizado na cultura brasileira. Porém, tem como fonte a forma como o Ensino a Distância lida com os desafios que surgem decorrentes de sua estrutura pedagógica. Uma das principais barreiras para a aceitação dos cursos de graduação do EAD está na qualificação e na formação dos professores envolvidos no processo.

\section{Metodologia}

A metodologia aplicada neste trabalho foi um estudo descritivo de natureza quali- quanti realizado através do instrumento de pesquisa entrevista. Segundo Malhotra (2004), uma pesquisa pode ser orientada em seis diferentes etapas: definição de problema, desenvolvimento da abordagem, formulação da concepção da pesquisa, coleta de dados, preparação e análise de dados, preparação e apresentação do relatório.

Segundo Lakatos e Marconi (2010), as abordagens qualitativas têm o poder de analisar aspectos complexos de fenômenos sociais considerando o contexto, buscando entender as experiências humanas de forma pessoal ou grupal.

Para Leite (2008, p. 94), “a divisão entre pesquisa qualitativa e quantitativa é apenas teórica, porque na prática toda e qualquer pesquisa usa os dois tipos de métodos sempre", sendo, portanto, pesquisas auxiliares uma da outra. Ainda segundo Leite (2008, p.96), as abordagens qualitativas "são as que empregam a estatística e a matemática - os números e cálculos - como principal recurso para a análise das informações”. 
De acordo com Gonçalves (2004), uma pesquisa não consiste simplesmente da divulgação dos seus resultados para o público, mas também na contribuição para o aprofundamento e a compreensão com relação a um determinado tema abordado.

Para a mesma foi importante realizar uma pesquisa descritiva, pois segundo Cervo e Bervian (2002, p.66), este tipo de pesquisa "busca conhecer as diversas situações que ocorrem na vida social, política, econômica e os demais aspectos do comportamento humano, tanto do indivíduo tomado isoladamente como de grupos e comunidades mais complexas". Fundamentar-se-á em pesquisa bibliográfica e de campo, com caráter exploratório.

Conforme dado o objetivo geral deste trabalho, procurou-se evidenciar a expansão do ensino à distância e os desafios para assegurar a qualidade na graduação, em Instituições de Ensino Superior (IES) localizadas em Juazeiro do Norte - CE. Para tanto, optou-se por aplicar como instrumento de coleta de dados uma entrevista, onde o pesquisador realizara perguntas abertas e fechadas, que foram respondidas por meio de aplicação de questionário estruturado aos alunos das IES entre os dias 04 de julho a 15 de outubro de 2019.

O autor Leite (2008) afirma que a entrevista é uma conversa verbal face a face que permite ao entrevistador coletar informações para a pesquisa. Os dados coletados serão analisados por meio da interpretação das respostas obtidas, através da análise de conteúdo que segundo o pensamento de Gil (2017) visa descrever de forma objetiva, sistemática e qualitativa o conteúdo manifesto da comunicação.

A entrevista foi elaborada com perguntas voltadas para compreender a percepção que os alunos matriculados nos cursos de graduação à distância têm sobre essa modalidade de ensino. Optou-se por aplicar a entrevista em quatro IES localizadas em Juazeiro do Norte CE.

O questionário foi composto por 10 questões e foram assim distribuídas: categorização dos alunos pesquisados, percepção dos alunos quanto aos tutores e professores, opinião sobre recursos midiáticos utilizados pelos entrevistados, questões sobre vantagens e desvantagens no EAD e o nível de satisfação com o curso.

\section{Análise dos Resultados}

Conforme o que foi descrito na metodologia para tornar mais transparente a análise dos resultados, a pesquisa foi dividida, as quais serão relatadas a seguir. 


\section{Categorização dos alunos pesquisados}

A amostra da pesquisa foi formada por 40 alunos matriculados em cursos de graduação à distância em IES de Juazeiro do Norte - CE, demonstrados nos gráficos abaixo.

Gráfico 1 - Idade.

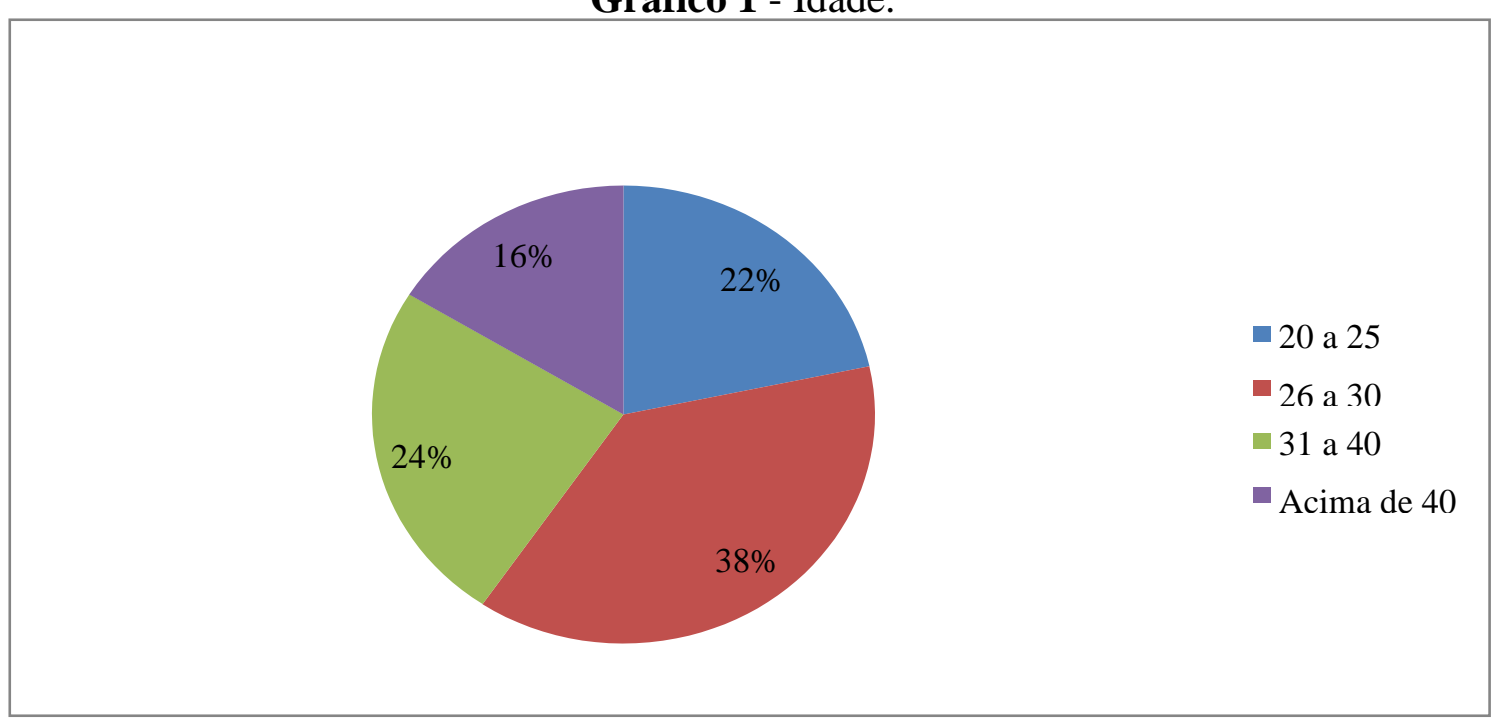

Fonte: Dados da Pesquisa (2019).

Com relação à idade dos alunos, percebe-se no Gráfico 1 que 38\% estão com mais de 25 anos, típico aluno online, que geralmente está empregado, preocupado com alguma formação na educação superior.

O Gráfico 2, a seguir, responde ao questionamento em relação a qual curso a distância o respondente da pesquisa estar matriculado na IES.

Gráfico 2 - Cursos matriculados na IES.

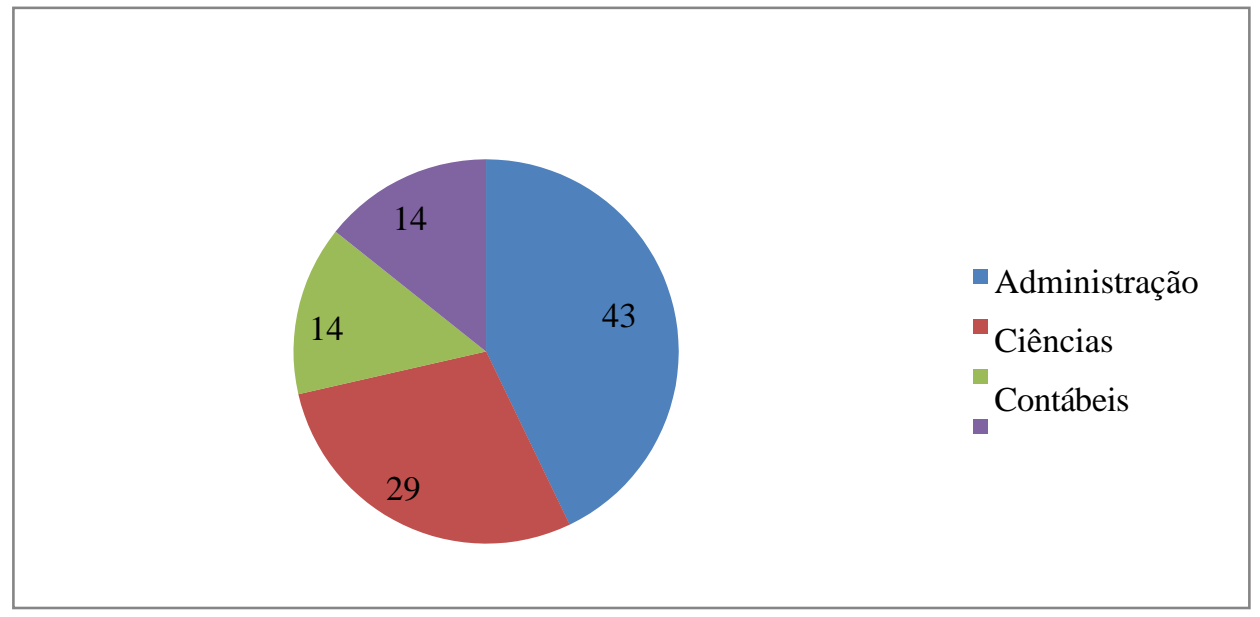

Fonte: Dados da Pesquisa (2019). 
Este dado demonstra que a maioria dos alunos matriculados no ensino à distância escolheu o curso de Administração e que os cursos da área de gestão estão entre os mais procurados, o que se pode verificar então que estão buscando se qualificarem para obter uma capacidade melhor sobre o mercado onde atuam ou desejam atuar.

\section{Percepção dos alunos quanto aos tutores e professores}

Na segunda parte desta pesquisa buscou-se analisar a percepção dos alunos a respeito dos tutores e professores no curso de graduação no qual está matriculado.

O Gráfico 3 apresenta os resultados de como os alunos do ensino a distância acham que é a comunicação com os professores e/ou tutores por meio do ambiente virtual.

Gráfico 3 - Comunicação com professor no ambiente virtual

\section{Como é a comunicação com os professores no ambiente virtual}

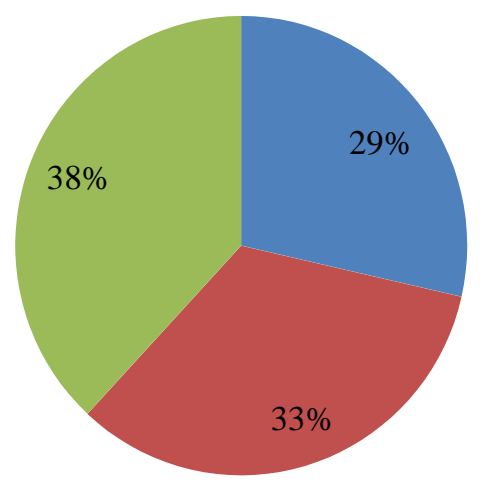

- Nada boa

Muito boa

$\square$ Boa

Fonte: Dados da Pesquisa (2019).

Conforme o Gráfico 3, 33\% dos alunos consideram que a comunicação com os professores ou tutores no ambiente virtual é muito boa, porque sempre que precisam obtêm respostas e os professores ou tutores são sempre muito atenciosos.

Já 38\% dos alunos que consideram como boa essa comunicação informam que sempre quando têm alguma dúvida sobre como abrir um link para fazer uma atividade, o professor ou tutor respondeu com prontidão e aprendem muito pelo ambiente virtual e ainda sem sair de 
casa que é o mais importante devido a família. E 29\% dos alunos justificaram que o AVA se torna extremamente confuso e não tiveram nenhuma instrução de como fazer as atividades.

\section{Gráfico 4 - Envolvimento com o Tutor}

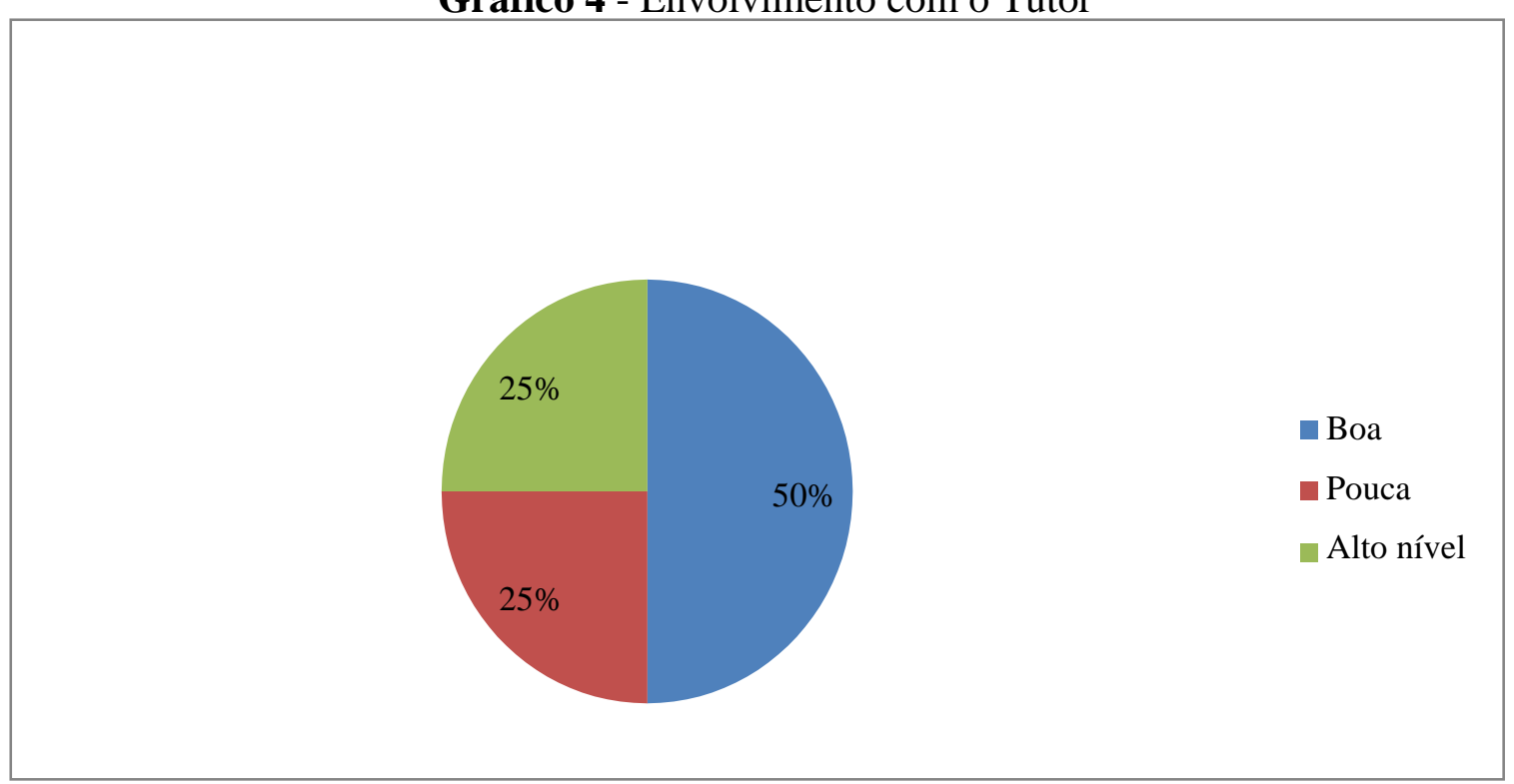

Fonte: Dados da Pesquisa (2019).

Questionou-se o envolvimento do tutor ou professor na aprendizagem do estudante, de modo que $25 \%$ dos respondentes assinalaram que a participação foi de alto nível, fornecendo suporte acima do esperado. $50 \%$ dos entrevistados responderam que há uma boa participação do tutor ou professor, fornecendo suporte necessário e os outros $25 \%$ que houve pouca participação do tutor ou professor na aprendizagem.

Gráfico 5 - Como são os Feedbacks recebidos durante o curso

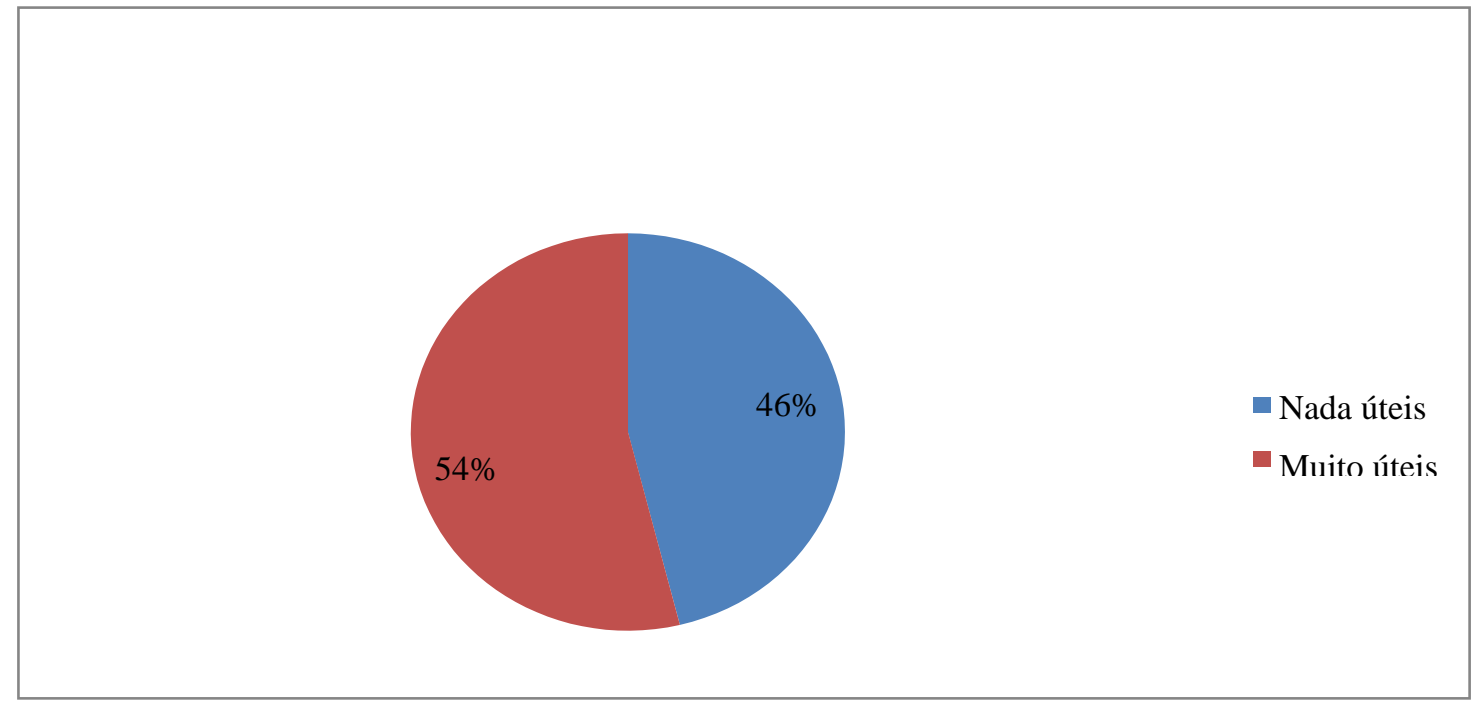

Fonte: Dados da Pesquisa (2019). 
Pode se observar no Gráfico 5, que 54\% dos alunos avaliam como muito úteis os feedbacks dados, que são bons, têm retorno produtivo, porém há uma demora em algumas respostas, e $46 \%$ consideram o feedback nada útil, que geralmente são vazios, informam somente a nota e demoram a dar um retorno.

\section{Opinião sobre recursos midiáticos utilizados pelos entrevistados}

Nessa questão foram oferecidas dez alternativas e foi solicitado aos respondentes que assinalassem quais recursos são ou foram utilizados em seu curso com possibilidade de assinalar quantas alternativas considerassem necessárias. Caso o recurso não estivesse listado foi deixado espaço para que acrescentassem "outros recursos utilizados".

Gráfico 6 - Recursos de aprendizagem utilizados no curso.

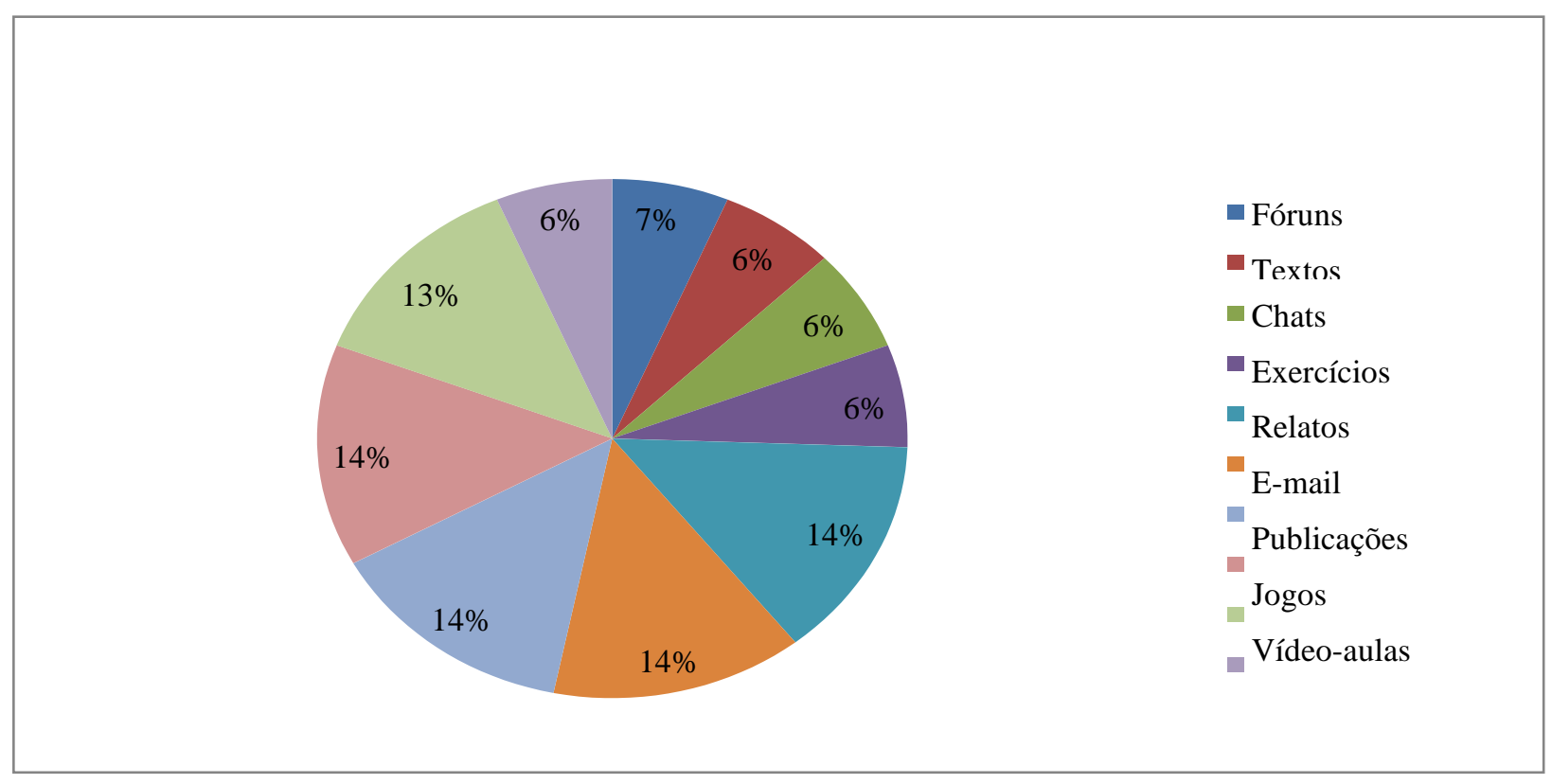

Fonte: Dados da Pesquisa (2019).

Os recursos mais utilizados pelos respondentes foram publicações, e-mails, relatos e jogos, seguido pelos chats. O resultado demonstra ainda que as instituições tiveram o cuidado de utilizar vários meios de comunicação mediada por computador para facilitar o ensino.

Como a questão era semiaberta, alguns entrevistados destacaram outros recursos utilizados: trabalhos em grupo, apostilas impressas, CDs, trabalhos individuais e reuniões online, considerados muito importantes pelos estudantes. 


\section{Questões sobre vantagens e desvantagens na EAD}

Sobre este assunto foram feitas duas questões, os resultados foram comentados, tabulados e representados por gráficos. O Gráfico 7 apresenta quais as vantagens que os alunos de EAD identificam nessa modalidade de ensino.

Gráfico 7 - Vantagens de realizar cursos EAD.

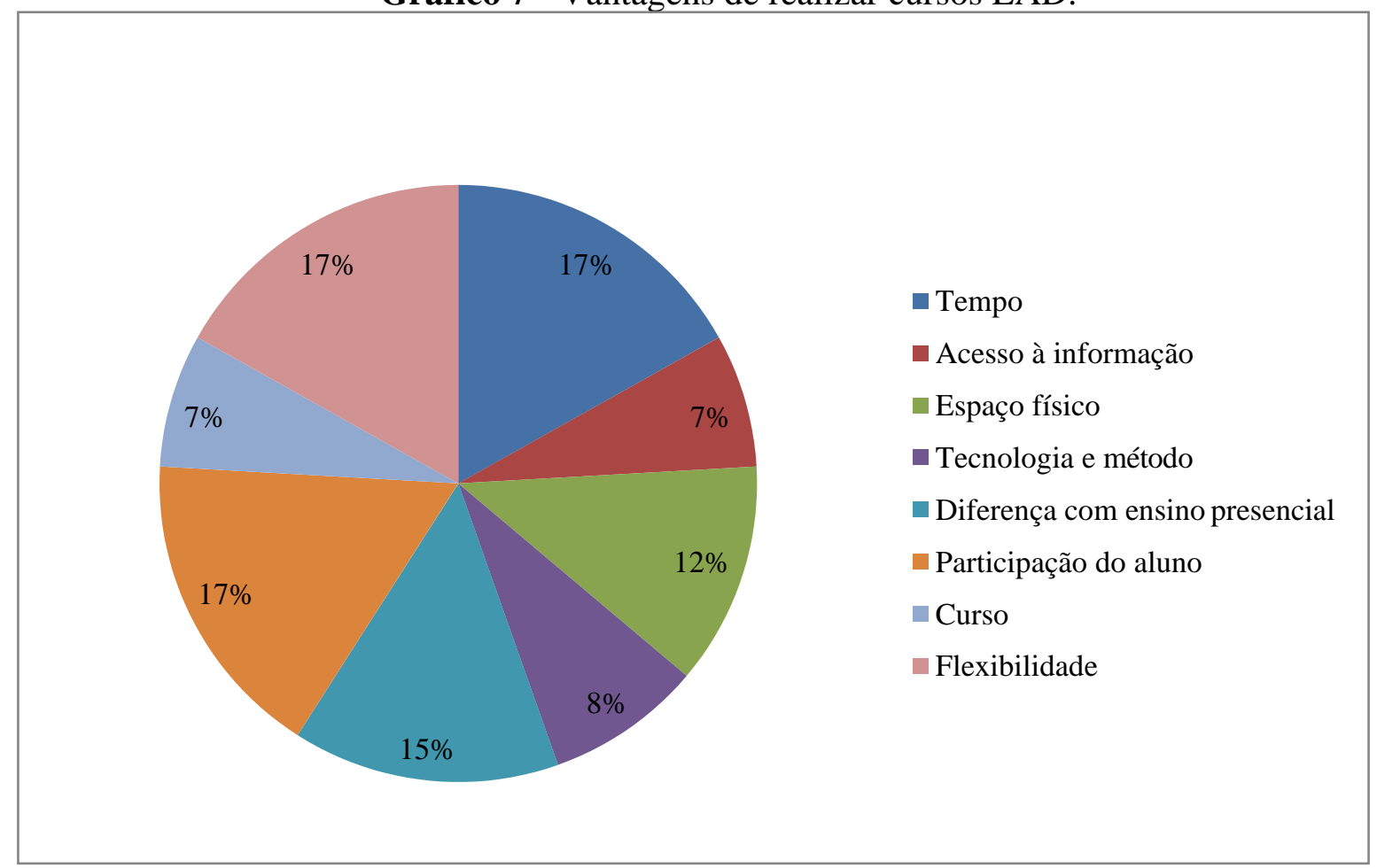

Fonte: Dados da Pesquisa (2019).

Relacionadas ao tempo, $17 \%$ dos entrevistados indicaram vantagens quanto à administração do tempo e horários, sendo que a palavra flexibilidade também foi incluída e pode ser considerada vantagem de tempo. Relacionadas ao acesso à informação, $7 \%$ dos entrevistados citaram o acesso à informação como vantagem, assim também como as mídias utilizadas e as pesquisas online.

Em relação ao espaço físico, a questão do deslocamento também foi incluída ficando entre as vantagens de $12 \%$ dos entrevistados, a possibilidade de fazer o curso em casa e no caso de mudança de cidade não há desistência das aulas. Relacionadas à tecnologia e ao método, $8 \%$ dos alunos ressaltaram este fator como vantagem, podendo recuperar o assunto tratado em algum encontro do qual não se participou, acervo das aulas interativas. 
Outro aspecto é com relação as diferenças com o ensino presencial, 15\% dos respondentes apontaram alguma diferença entre o ensino presencial, destacando tratar uma disciplina por vez como útil. De acordo com o estímulo à participação do aluno, $17 \%$ se sentiram estimulados e entenderam como vantagem, no sentido da obrigatoriedade de participação em sala de aula, atividades, fóruns e chats. Ao se analisar o curso, $7 \%$ dos respondentes citaram como vantagem os baixos custos, como alimentação e transporte, economia e praticidade.

Também foi incluída a alternativa nenhuma, pois alguns alunos afirmaram não sentir nenhuma vantagem nos cursos à distância, não conseguem assimilar e aceitar este tipo de curso, pois sentem grande dificuldade de aprendizagem à distância.

\section{Gráfico 8 - Desvantagens de realizar cursos EAD}

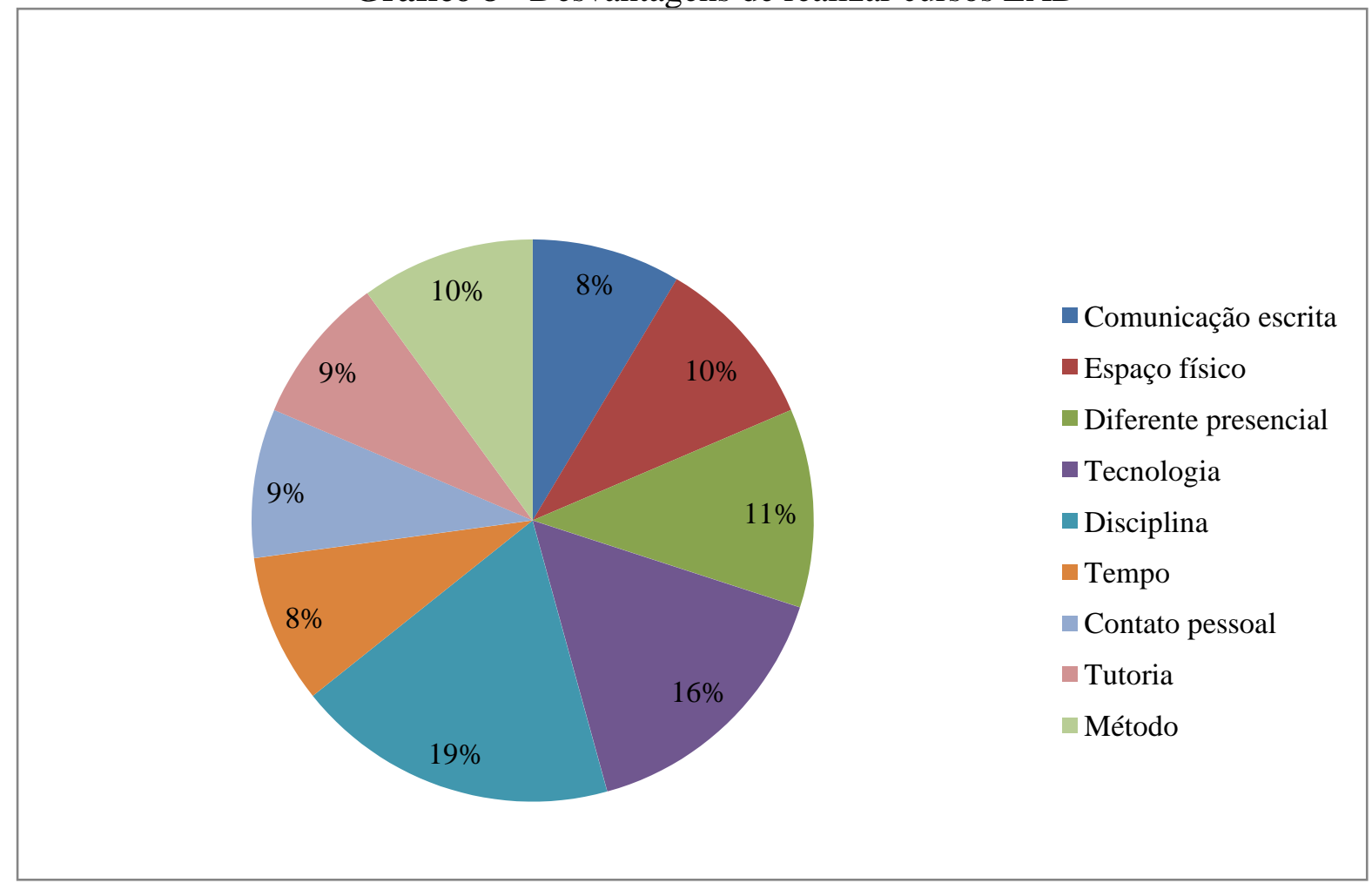

Fonte: Dados da Pesquisa (2019).

Relacionadas ao tempo, $8 \%$ dos entrevistados destacaram principalmente os horários fixos dos chats e o excesso de atividades pelo pouco prazo e o pressuposto de que se leu, entendeu. O curso passa por cima e segue adiante. Para a disciplina, 19\% dos entrevistados destacaram a necessidade, ou falta de disciplina para acompanhar a curso, manter a disciplina de participação efetiva e cumprimento de tarefas propostas, conteúdo muito complexo em 
relação ao cronograma proposto para algumas disciplinas. Trata-se do autocontrole para priorizar o estudo em detrimento do lazer.

Quanto ao espaço físico, foi citado por $10 \%$ dos respondentes como desvantagem, principalmente na dificuldade de separar a família do estudo, respeito pelos horários dos chats por parte dos familiares. Considerando os problemas técnicos e de equipamentos, $16 \%$ dos alunos sentiram que a tecnologia prejudica seus estudos, problemas de comunicação, sistema lento, quedas na conexão, algumas demoras nos retornos das dúvidas dos fóruns, problemas estruturais apresentados na plataforma.

Sobre ao método, a maior parte das queixas relacionou-se à dificuldade em se adaptar ao ensino à distância, desencontro de informações, respostas não instantâneas e metodologia. Questionou-se às diferenças com o ensino presencial, o fato de ser diferente foi lembrado por $11 \%$ dos respondentes, falta de uma resposta mais rápida como ocorre com o professor em sala de aula no caso de esclarecimentos de dúvidas e sugestões.

Relacionadas à falta de contato pessoal e interação, este item foi destacado, sendo que grande parte se referiu às dificuldades na realização de trabalhos de grupo, interação entre os alunos e coordenação do curso, sentimento de isolamento. Na percepção à tutoria, problemas com professores e tutores foram abordados por $9 \%$ dos respondentes, alguns tutores tomavam conhecimento sobre a disciplina ao mesmo tempo em que os alunos, faltando uma preparação prévia, difícil contato para tirar dúvidas com os tutores, principalmente em relação aos cálculos.

\section{Nível de satisfação com o curso}

Essa questão buscou saber de maneira direta se os entrevistados estavam ou não satisfeitos com a realização de seus cursos, destacando que o objetivo não foi o de avaliar se uma instituição ou outra obteve melhores resultados, e sim verificar a aceitação dos alunos quanto à modalidade de ensino, considerando que ainda existe pouco material mensurando a satisfação dos aprendizes do EAD. 
Gráfico 9 - Avaliação dos alunos em relação ao ensino EAD

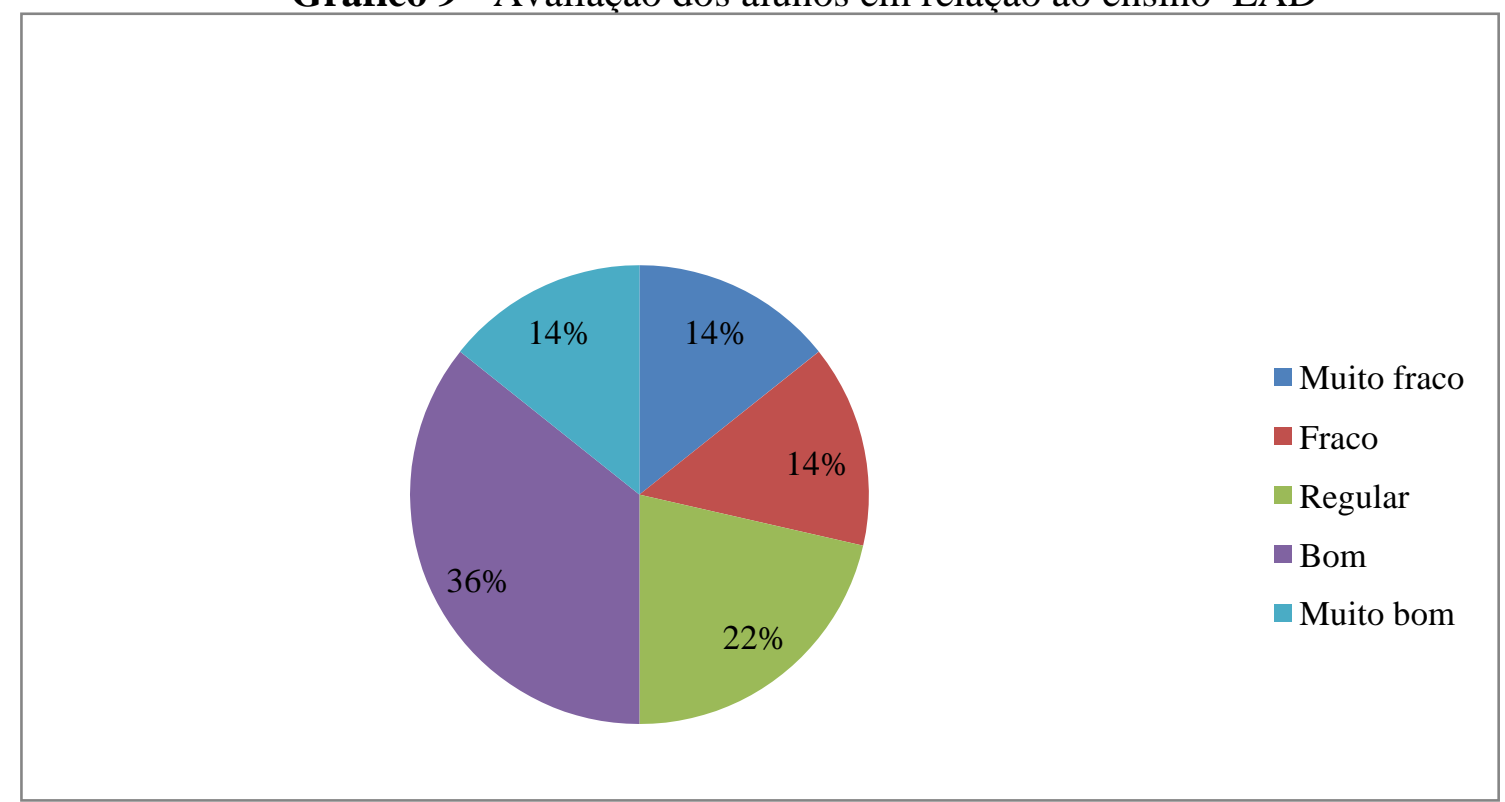

Fonte: Dados da Pesquisa (2019).

Embasado no Gráfico 9, observa-se que apesar de os números demonstrarem que $36 \%$ dos alunos respondentes avaliaram o curso como bom, revela-se uma necessidade de uma releitura de algumas ações em relação ao número de alunos que avaliaram como regular.

O Gráfico 10 revela o grau de satisfação dos respondentes em relação aos cursos que estão cursando.

Gráfico 10 - Grau de satisfação

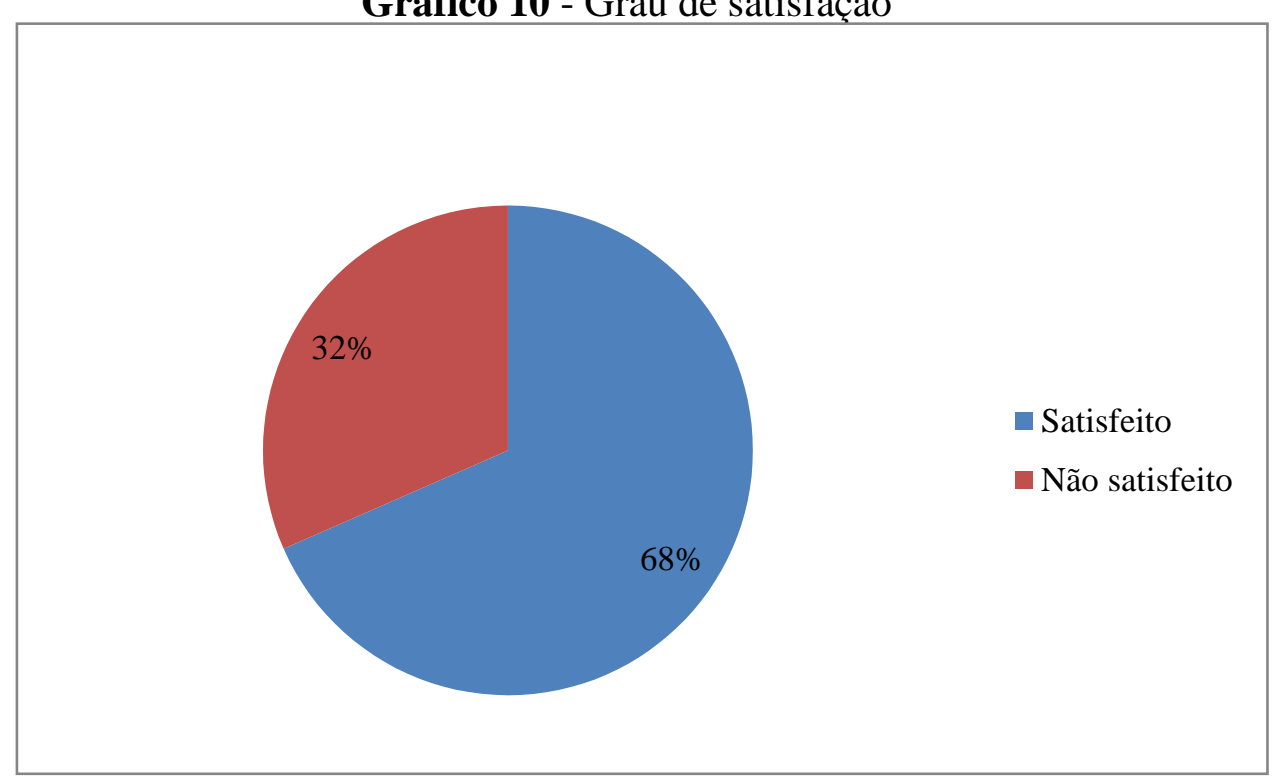

Fonte: Dados da Pesquisa (2019). 
O resultado obtido no Gráfico 10 indica um grau de satisfação de $68 \%$ na percepção dos entrevistados. Apesar de a maior parte dos alunos demonstrarem-se satisfeitos, o estímulo, a didática e as melhores formas de persuadi-los devem ser revistas constantemente, visto que, nesta modalidade de ensino, a persistência do aluno assume papel circunstancial e também está implícita a sua própria motivação.

\section{Considerações Finais}

O presente estudo teve como objetivo identificar a expansão do ensino à distância e os desafios para assegurar a qualidade na graduação em IES localizadas na cidade de Juazeiro do Norte - CE. A fim de embasá-lo, buscou-se fazer uma entrevista comalunos matriculados nos cursos de graduação à distância em quatro IES para a finalidade de obter os resultados necessários com sua aplicação.

Buscou-se apresentar os resultados obtidos com a pesquisa realizada quanto ao perfil dos estudantes, vantagens e desvantagens da EAD, opinião quanto à tutoria e ainda o nível de satisfação dos entrevistados com a modalidade de educação à distância.

Percebeu-se que a modalidade EAD é o maior avanço das últimas décadas para a democratização do acesso ao ensino e que é crescente a oferta de cursos nessa modalidade na região. De acordo com os dados demográficos, os alunos com mais de 25 anos demonstraram ter maior interesse para esse tipo de ensino.

A pesquisa realizada apontou que os alunos que cursam cursos de graduação à distância consideram os tutores e professores muito importantes e que as características pessoais e pedagógicas mais apreciadas neles são o fornecimento de feedback e o estímulo à aprendizagem, fornecendo suporte necessário.

Os recursos tecnológicos que propiciaram melhores experiências de aprendizagem foram os chats, reuniões online, jogos e publicações. As principais dificuldades encontradas pelos respondentes no EAD estão relacionadas principalmente quanto à disciplina, a participação efetiva e cumprimento de tarefas propostas e o autocontrole para priorizar o estudo, já as principais vantagens estão relacionadas à flexibilidade de tempo e espaço físico.

Nessa modalidade de ensino são necessários metodologias e recursos muito diferentes dos usualmente utilizados nos cursos presenciais, constituindo um desafio tanto para os professores como para os próprios alunos. 


\section{Referências}

ARETIO, L.G. Bases, mediaciones y futuro de la Educación a distancia em la sociedade digital. Madrid: Editorial Síntesis, 2014.

CERVO, A. L.; BERVIAN, P. A. Metodologia Científica. 5aed. São Paulo: Pearson Prentice Hall, 2002.

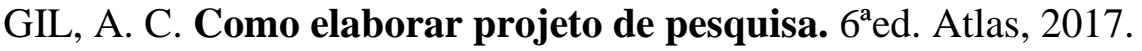

GONÇALVES, H. de A. Manual de artigos científicos. São Paulo: Avercamp, 2004.

INSTITUTO NACIONAL DE ESTUDOS E PESQUISAS EDUCACIONAIS ANÍSIO TEIXEIRA (INEP). Resumo Técnico do Censo da Educação Superior. 2013. Disponível em http://download.inep.gov.br/download/superior/censo/2013/resumo_tecnico_censo_edu cacao_superior_2013.pdf. Acesso em: agosto 2019.

\section{INSTITUTO NACIONAL DE ESTUDOS E PESQUISAS EDUCACIONAIS ANÍSIO} TEIXEIRA (INEP). Indicadores de Fluxo do Ensino Superior. 2017. Disponível em: http://portal.inep.gov.br/ artigo/-/asset_publisher/B4AQV9zFY7Bv/content/inepdisponibiliza-indicadores-de-fluxo-da-educacao-superior/21206. Acesso em: março 2019.

LAKATOS, E. M.; MARCONI, M.A. Metodologia Científica. 5aed. São Paulo: Atlas, 2010.

LEITE, F. T. Metodologia Científica: métodos e técnicas de pesquisa - monografias, dissertações, teses e livros. Aparecida, São Paulo: Ideias e Letras, 2008.

LEITE, S.S.F; ROSA, M.B. O comportamento autônomo dos alunos da educação à distância e a construção do conhecimento. São Paulo: v. 1, n.2, 2017

LOBO NETO, F.J da S. Educação à Distância - Referências e Trajetórias. $1^{\text {a ed. ABT }}$ - Associação Brasileira de Tecnologia Educacional, 2002.

MALHOTRA, N. K. Pesquisa de marketing: uma orientação aplicada. $4^{\text {a }}$ Ed. Porto Alegre: Bookman, 2004.

MINISTÉRIO DA EDUCAÇÃO (MEC). Regulamentação da EAD no Brasil. Disponível em: http://portal.mec.gov.br/seed/index.php. Acesso em: 28 de julho de 2019.

PINO, A. S. Educação à distância: propostas pedagógicas e tendências dos cursos de graduação. Tese (doutorado) - Universidade Nove de Julho. São Paulo. 2017.

RIBAS, C. O profissional da informação: rumos e desafios para uma sociedade inclusiva. Informação \& Sociedade, João Pessoa, v. 17, n. 3, set./dez. 2007, p47-57.SANTOS, P. K.; SANTOS, E. R. dos; OLIVEIRA, H. de. Educação e Tecnologias. Porto Alegre: SAGAH, 2017. 
VALENTE, J.A. O ensino híbrido veio para ficar. In: BACICH, L; TANZI NETO, A; TREVISANI, F. De M. (Org). Ensino híbrido: personalização e tecnologia na educação. Porto Alegre: Penso, 2015.

VIANNEY, J; TORRES, P.; SILVA, E. A Universidade virtual no Brasil: o ensino superior à distância no país. Tubarão, SC: Unisul, 2003.

\section{Como citar este artigo (Formato ABNT):}

SANTOS, Francisca Jacqueline Soares dos; LIMA, Marcus Emanuel Oliveira; SARAIVA, Piedley Macedo. A expansão do ensino a distância e os desafios para assegurar a qualidade na graduação: Um estudo realizado com Instituições de Ensino Superior em Juazeiro do Norte-CE. Id on Line Rev.Mult. Psic., Maio/2020, vol.14, n.50, p. 195-213. ISSN: 1981-1179.

Recebido: 31/03/2020.

Aceito: 05/03/2020 